This item was submitted to Loughborough's Research Repository by the author.

Items in Figshare are protected by copyright, with all rights reserved, unless otherwise indicated.

\title{
Mind the gap: a grounded theory of dual career pathways in sport
}

PLEASE CITE THE PUBLISHED VERSION

https://doi.org/10.1080/10413200.2019.1654559

PUBLISHER

Taylor \& Francis

\section{VERSION}

AM (Accepted Manuscript)

\section{PUBLISHER STATEMENT}

This is an Accepted Manuscript of an article published by Taylor \& Francis in Journal of Applied Sport Psychology on 3 September 2019, available online:

http://www.tandfonline.com/10.1080/10413200.2019.1654559.

\section{LICENCE}

CC BY-NC-ND 4.0

\section{REPOSITORY RECORD}

Deason, Emily, David Fletcher, Christine Coupland, and Guy Taylor. 2019. "Mind the Gap: A Grounded Theory of Dual Career Pathways in Sport". Loughborough University. https://hdl.handle.net/2134/9884753.v1. 
Mind the Gap: A Grounded Theory of Dual Career Pathways in Sport Emily Deason, David Fletcher, and Christine Coupland Loughborough University Guy Taylor Talented Athlete Scholarship Scheme

\section{(1)}

7

Emily Deason and David Fletcher, School of Sport, Exercise and Health Sciences, Loughborough University, United Kingdom; Christine Coupland, School of Business and 4 Economics, Loughborough University, United Kingdom; Guy Taylor, Talented Athlete Scholarship Scheme, Newcastle Upon Tyne. United Kingdom.

\footnotetext{
Abstract

The purpose of this study is to identify and examine individuals' experiences of and the outcomes of sport and education or vocational development, with the intention to establish an overarching theory of dual career (DC) pathways in sport. Since the contrasting experiences and outcomes of a DC are largely unguided by a theoretical model, the grounded theory method was selected to address the research aim. 17 DC athletes took part in a lifestory interview, which were analysed, along with previous literature, to develop a conceptual understanding of the research area. The findings that emerged from this study supported a categorisation of DC experiences into three pathways: a sporting pathway, an
} 
1 educational/vocational pathway, and a dual career pathway. These pathways are visually

2 represented in a figure. The overarching themes of these pathways were encompassed into

3 three vignettes and the outcomes of each pathway are discussed. The developed grounded

4 theory presents a conceptualisation of different DC development pathways, the practical

5 implications likely to be associated with these pathways and provides a framework for future

6 research.

7

Keywords: athletic development, athletic identity, career development, career identity;

8 student athlete; transition.

9

10

11

12

13

14

\section{Lay Summary}

The study develops a theory of DC pathways and the outcomes via a method known as grounded theory. Three main pathways were identified: a DC pathway, a sporting pathway, and an educational/vocational pathway. Each pathway is associated with various outcomes and considerations for research and practice. 
Mind the Gap: A Grounded Theory of Dual Career Pathways in Sport Most sport performers, except full-time professional athletes, pursue their sport ambitions alongside an education or a vocation. Youth athletes engage with compulsory education and, in later adolescence, the majority either pursue further/higher education or employment. This twin pathway of sport and education or vocational development - referred to as dual career (DC) in the sport psychology literature - represents a formative stage in an individual's life in terms of their physical, psychological, and social development. The initial research on DC in sport did not begin with a specific focus on DC athletes per se. It emerged from work investigating the transitions in athletic development while recognizing the importance of a holistic perspective of athletes rather than a sole focus on them as sport performers (see Petitpas, Brewer, \& Van Raalte, 1996; Wylleman, Alfermann, \& Lavallee, 2004; Wylleman \& Lavallee, 2004). Research initiated a specific focus on DC in sport, which included the European Union publishing recommended policy actions in support of DCs in high-performance sport (European Union Expert Group: Education and Training in Sport, 2012) and the Psychology of Sport and Exercise publishing a Special Issue on DC Development and Transitions (Stambulova \& Wylleman, 2015). A DC athlete is defined as an individual who pursues sport and education or vocational endeavours.

Previous research has identified a variety of benefits associated with pursuing education or vocational endeavours alongside sport, including a sense of well-being brought about through developing a multi-dimensional identity (Miller \& Kerr, 2002; Pink, Lonie, \& Saunders, 2018; Ryba, Stambulova, Ronkainen, Bundgaard, \& Selänne, 2015). The presence of an alternative focus has also been described as a relief from the pressures of sport and provides perspective to the individual (Aquilina, 2013; Pink, Styne, \& Saunders, 2015). Indeed, the benefits can extend beyond the athletic career itself and a DC has been associated with positive athletic retirement (Brewer, Van Raalte, \& Petitpas, 2000; Taylor, Ogilvie, \& 
1 Lavallee, 2005), increased life satisfaction after sport (Lavallee \& Robinson, 2007), and an

2 increased ability to make post-sport decisions (Murphy, Petitpas, \& Brewer, 1996). With an

3 increasing number of higher education systems hosting high performance centres, DC

4 athletes could also benefit from utilising higher education systems' support services and

5 facilities to advance their own athletic and personal development (Brown, Fletcher, Henry,

6 Borrie, Emmett, Buzza, \& Wombwell, 2015). DC athletes have described elevated levels of

7 motivation to maintain both sporting and educational or vocational endeavours to obtain these

8 benefits (Aquilina, 2013; Cosh \& Tully, 2014).

Although the positive experiences of a DC have been demonstrated, the negative aspects of pursuing two career goals have also been extensively reported. A body of research has referred to the implausibility of DC pursuits due to the high time demands and intense pressures on physical and mental energy (Cosh \& Tully, 2014; Singer, 2008; Tekavc, Wylleman, \& Cecić Erpič, 2015). The ability to manage a DC is described as heavily dependent on support from significant others (Knight, Harwood, \& Sellars, 2018). As a consequence of these challenges, DC individuals have reported feeling compelled to compromise one of their pursuits (Ryan, 2015; Ryba et al., 2015; Tekavc et al., 2015). This compulsion was often influenced by perceived pressure from sporting stakeholders to prioritise sport as a necessity to achieving elite status (Ryan, 2015), despite a common understanding that sacrificing academic achievements has consequences for academic grades, confidence in academic tasks, and career decision-making skills (Bimper, 2014; Melendez, 2009; Murphy et al., 1996). The research also reports DC individuals sacrificing their sporting goals in favour of educational or vocational goals due to barriers in reaching the toplevel of sport, including the ability to financially sustain themselves (Brown, GlastetterFender, \& Shelton, 2000; Isoard-Gautheur, Guillet-Descas, Gaudreau, \& Chanal, 2015). 
There is an emerging body of research that has focused on the individual differences seen in DC athlete's experiences and their career trajectories. Following a systematic review of the qualitative research in this area, Li and Sum (2017) identified three overarching factors relating to DC athletes' experiences: individual (viz. physical conditions, psychological conditions), interpersonal (viz. social agents, coping strategies), and external (e.g., opportunity, support, barriers, financial). These factors contribute to or inhibit DC development in sport and emphasise the importance of both the individual and the environment in facilitating the DC experience. However, although Li and Sum (2017) highlighted that "each athlete has their own pathway to managing their [sic] dual careers and... trajectories" (p. 112), these pathways are not outlined in their model. Stambulova, Engström, Franck, Linnér, and Lindahl (2015) established a continuum of experiences, from prioritizing sport (and higher visibility of athletic identity) at one end to prioritizing studies (and higher visibility of student identity) at the other end, in their quantitative study of school-aged athletes. Whereas, Ryba, Stambulova, Selänne, Aunola and Nurmi (2017) used narrative methods to identify three styles that junior athletes used to construct their projective careers, including a perception that sport and education hold an interdependent relationship with each other (i.e., a contrapuntal career) and a perception of one pursuit as more dominant (i.e., a monophonic career). Aunola, Selänne, Selänne, and Ryba (2018) introduced three motivational categories of DC athletes which are characterized by a high value placed on both school and sport, a low academic motivation, and a (relatively) low sport motivation through their investigation with school aged athletes.

While the recent research indicates the understanding of DC athletes as a heterogeneous group, these studies have, however, largely focused on junior level or schoolaged athletes. Debois, Ledon, and Wylleman (2015) emphasised that DCs are inherently developmental in nature, encompassing sport and education or vocational transitions at 
1 different stages of the lifetime, and highlighted the importance of adopting a holistic, lifespan

2 perspective when considering DC athletes. Hence, despite these observations, the specific

3

4

5

6 experiences and outcomes that underpin the Janus-faced nature of DC endeavours across the lifespan requires further theoretical explanation. The purpose of this study is, therefore, to identify and examine individuals' experiences and outcomes of sport and education or vocational development, with the intention to establish an overarching theory of DC pathways. It is intended that a greater understanding of this area will provide a more robust evidence-base to support individuals in their sporting, educational, and vocational development.

\section{Methods}

\section{Approach to Inquiry}

The grounded theory method was proposed by Glaser and Strauss (1967) as a method to inductively generate theory from data with the aim to develop a higher-level understanding of phenomena. As the current research aims to investigate the lifespan of a DC athlete through establishing an overarching theory of DC pathways and the outcomes of these pathways, a grounded theory methodology was considered appropriate. This study adopts a constructivist grounded theory approach as it is consistent with the researchers' ontological and epistemological views of the world and knowledge acquisition. Furthermore, the constructivist variant offers several strengths, including flexible data collection and interpretation strategies which emphasise the co-construction of knowledge and ensure that the emergent theory remains grounded within the data (Creswell, 2007; Mills, Bonner, \& Francis, 2006). Charmaz's constructivist variant of grounded theory, in particular, encourages the researcher to conduct and present research in a way that resonates with the data. Hence, this variant "retains the fluidity and open-ended character of pragmatism" (Charmaz, 2006, p.184). As a result, this study engages with narrative approaches in the data collection, via 
1 interviews based on a life story approach, and in the data reporting, via vignettes. A more

2 detailed outline of a constructivist grounded theory methodology is found in Charmaz's

3 (2006) guide.

\section{Study Participants}

Participant selection process. Before commencing, ethical approval for the research design and procedure was obtained. Potential participants were initially recruited by the first author either via email or approached in person. First, the researchers adopted a broad approach to recruitment by seeking any individual with experience of a DC. After 3 interviews theoretical sampling was used to purposefully select participants who had the potential to contribute to the emerging concepts or address gaps in our understanding (Creswell, 2007; Robinson, 2014). For example, after discussions with an individual around the events that led to them questioning their commitment to education and prioritizing sport, more participants were recruited to expand our understanding of this category. Through the theoretical sampling strategy, the researchers were also able to compare the experiences of individuals who perceived themselves to have not attained one or more of their sporting or educational/vocational career goals with individuals who perceived that they had. The use of negative cases has been recognised as an effective strategy for extending understanding (Patton, 2002) and, in this study, enabled the researchers to identify experiences that led to different DC outcomes. Towards the end of the study, giving consideration as to what determined an adequate sample size, the researchers were guided by the concept of theoretical saturation as opposed to the more traditional concept of data saturation. That is, data collection ceased when the ongoing process of constant comparison no longer brought fresh theoretical insights, or no longer extended insight into higher level concepts (Charmaz, 2006). 
Participant characteristics. The sample of participants comprised 17 individuals $(9$

male and 8 females) who had experiences of combining their aspirations towards an elite sports career with an alternative education or vocation. Further characteristics of the participants are summarised in Table 1. The sampling approach led to the recruitment of both retired and current DC athletes, and a large age-range between the participants 20 to 37 years $(\mu=27, \mathrm{SD}=5.36)$. The researchers restricted recruitment to participants who were identified, through competing at the national and international level, as having the potential ability, interest in, and commitment to elite sport (i.e., talented, high-level, or highperforming athletes). Participants represented a variety of sports (viz. canoeing, curling, cycling, hockey, rowing, rugby, tennis, triathlon, swimming, volleyball) and different vocational backgrounds (viz. accountant, coach, defence forces, journalist, life coach, lifestyle advisor, student, teacher). Not all participants held British nationality, but all were educated in the British system.

\section{Data Collection Strategies}

Charmaz's constructionist variant of grounded theory is considered to be "congenial with other approaches [of inquiry] such as...narrative analysis..." (Charmaz, 2006, p.184), furthermore the researcher is encouraged to consider the "entire narrative" of interviews (Charmaz, 2006, p.52). With this and the research question in mind, the current grounded theory adopts a semi-structured, in-depth interview based on a life-story approach in the data collection process in order to access higher-order understandings of the experiences of the lifespan of DC athletes. This method was selected to gain a holistic perspective of the DC individual's life history and noteworthy events that impacted their journey (Atkinson, 1998). An interview guide was used as a prompt for the researcher to aid the collection of information-rich data, but which included sufficient flexibility to allow the participant to introduce alternative points of discussion (Charmaz, 2006). Questions ranged from a broad 
1 overview of their experience (e.g., can you describe your DC experience so far?) to details

2 about specific events and how they impacted their pathway (e.g., can you explain in detail what happened? How do you think this impacted your journey? Did your attitude towards DC change after this?). Additional interview questions were developed during the data analysis to facilitate further understanding of the emerging theory (e.g., What were your goals when you first started for each of the pursuits? Have these changed?). Furthermore, the researcher shared their understanding of the key issues of the context with participants to aid the coconstruction of the theory. All interviews were conducted, digitally recorded, and then transcribed verbatim by the first author, who has personal knowledge of the DC experience and this was used to develop a relationship of reciprocity with the participants. The research process was supervised by the second and third authors who are experienced qualitative researchers. Each participant took part in one interview, which was conducted in a quiet, private location of the participant's choice. The length of the interviews ranged in duration from 45 to 90 minutes. The total duration of the data collection process was approximately six months and took place in 2017.

\section{Data Analysis Strategies}

Grounded theory analysis takes place through a non-linear, iterative process known as the constant comparison process (Charmaz, 2006), that fluctuates between inductive data collection and deductive understandings from previous literature and has been described as "the core category of grounded theory" (Hallberg, 2006, p.143). In this study, deductive data (i.e., previous literature) was avoided in the early stages of the research (i.e., before data collection or in the first 3 interview analysis) but was introduced in the later stages, (i.e., a delayed literature review and in the analyses of the following 14 interviews; Charmaz, 2006; Holt \& Dunn, 2004). This constitutes as theoretical sensitivity, which is considered crucial to grounded theory and refers to having awareness and understanding of the meaning of the data 
1 (Strauss \& Corbin, 1990), but is compromised by allowing the analysis to be guided by a

2 detailed review or specific theoretical framework (Glaser, 1992). Some theories that were

3 considered include career transition theory (Stambulova, 2003; Stambulova, Alfermann,

4 Statler, \& Côté, 2009), identity theory (Stryker, \& Burke, 2000), and athletic development

5 theories (Wylleman, Reints, \& De Knop, 2013).

6 The first author transcribed and analysed each interview transcript before collecting

7 further data. Although, there were a few instances where this was not possible because

8 interviews were conducted immediately after one another. Initially, coding was based on a

9 line-by-line analysis whilst remaining receptive to all possible interpretations. At this stage,

10 interview data was compared with other interview data for similarities and differences. As recurring codes emerged and an analytic direction was beginning to establish, coding became more directed, selective, and conceptual to explain larger segments of the data. Despite the described progression of coding, there was an element of fluidity in these stages where the researcher reverted to initial coding methods when new categories emerged or to define the boundaries of categories. The coding process was conducted by the first author but was supplemented by discussions with the second, third and fourth authors. The fourth author, a practicing expert, provided a practitioner's understanding from over fifteen years working within the research context at a policy level. This ensured the relevance of the developing theory (i.e., the three DC pathways) to the research area (Charmaz, 2006). These discussions led to the foundations of the theory and how it interlinked with most salient concerns of the context.

Analytic tools. Several analytic tools were used to aid the data analysis process.

Researcher's notes were recorded immediately after interviews which documented the researcher's initial thoughts about the relation of the interview to the emerging theory and the interaction between participant and researcher (Charmaz, 2006). Through the coding process, 
memos were used to explain categories; to explore relationships between data, codes, concepts, and categories; to aid the process of developing coding from initial to theoretical; and to encourage reflexivity from the researchers. Memo-writing has been described as a "pivotal intermediate step between data collecting and writing" (Charmaz, 2006, p. 72). Additionally, NVivo software was used to organise codes, concepts, and memos (Hutchison, Johnston, \& Breckon, 2010). As an understanding of categories developed, diagramming was also used to develop and locate the emerging theory and to illustrate more concrete images of the researchers' developing ideas (Charmaz, 2006). By engaging in this process, the researchers were able to conceptualize the ideas derived from the data and to visualise gaps in understanding which were evident in the emerging theory.

\section{Data reporting strategy}

The findings of the study are schematically presented in Figure 1. The research findings are also conveyed in the form of three stories and accompanying analysis sections. The use of creative non-fiction as a form of data reporting has increased in popularity within sport psychology in recent years (e.g., Champ, Nesti, Ronkainen, Tod \& Littlewood, 2018; Hings, Wagstaff, Anderson, Gilmore, Thelwell, 2018; Schinke, Blodgett, McGannon, Ge, Oghene \& Seanor, 2017). The narrative focus of this method enables the communication of contextualized research findings that emphasise the complexity, fluidity, and social nature of athletes' experiences. While there are multiple forms of vignettes used to present research findings (Blodgett, Schinke, Smith, Peltier, \& Pheasant, 2011), a composite vignette, as used in this study, comprises a mixture of accounts given by participants into one narrative (Spalding \& Phillips, 2007). Therefore, these vignettes should not be read as individual quotes but as an amalgamation of shared accounts. This particular form of vignette was selected because it enables the telling of a story over time with the use of specific examples of events whilst maintaining the anonymity of participants. Although the use of vignettes is 
not specifically described in the constructivist variant of grounded theory, Charmaz encourages grounded theorists to "make use of those rhetorical devices and writing strategies that mirror how you constructed your grounded theory" (Charmaz, 2006, pg 172). The reporting method was, therefore, selected as it promotes an understanding of the interconnection between the themes, and the participants' holistic experience over time (Ely, Vinz, Downing, \& Anzul, 2003). The authors created these stories through, first, collecting the interviews, using the developed theory (i.e., the three DC pathways) as a framework, into the pathway that best represented the experience of the interviewee. The codes and categories that arose from the analysis were then used to identify quotations that appeared to represent the narratives of each pathway. Quotes were then collected and connected with linking sentences and words. While the first author took the role of storyteller the second, third, and fourth authors supplemented this process with their discussions of the vignette content and fit with each of the pathways (Smith, 2016; Sparkes, 2002). Through this process, the vignettes are grounded in empirical data in order to resonate with readers and to move them toward new understandings (O'Malley, Winter, \& Holder, 2017; Blodgett et al., 2011).

\section{Research Quality}

The assessment of methodological integrity within qualitative research is a debated topic. For this study, the researchers aimed to achieve trustworthiness through methodspecific considerations (Burke, 2016; Levitt, Motulsky, Wertz, Morrow, \& Ponterotto, 2017). This approach is in keeping with Charmaz's (2006) guide for conducting constructivist grounded theory and draws upon elements of Weed $(2009,2010,2017)$ and Holt and Tamminen's (2010) debates around quality in grounded theory research within sport psychology. Although the constructivist grounded theory variant incorporates Glaser and Strauss's (1967) criteria of fit, work, and relevance for evaluating research quality, Charmaz (2006) also adds a set of paradigm-specific criteria: credibility, originality, resonance, and 
usefulness. The credibility of this research is enhanced through the use of a diverse sample with both male and female participants from a variety of sporting and educational backgrounds. Originality of the research is established through addressing a particular research gap, in this case the exploration of diverse DC experiences through a lifespan perspective. Resonance with the practitioner context and encompassing the multitude of DC experiences was a specific focus of the sampling procedure. Finally, drawing upon the experiences of a practicing expert has ensured that emergent theory is both relevant and useful to the 'real-world' context (Charmaz, 2006; Levitt et al., 2017).

\section{Findings and Analysis}

The following findings derived from the data collection and analysis process and are presented via three composite vignettes, accompanying analysis sections, and Figure 1. In general, a DC begins during compulsory education where individuals start to transition from the initiation stages of an athletic career to the development stages and begin to develop sporting goals of becoming an elite athlete (Wylleman et al., 2013). Most participants in this study found the combination of sport and compulsory education (e.g., primary or secondary school) challenging but found that they were able to manage due to being surrounded by individuals who were willing to support both their pursuits. A DC was described as increasingly difficult during higher education and employment. This led to some participants reducing their commitment to at least one of their career ambitions. A reduced commitment to one endeavour is categorised in this study as either a sporting pathway or an educational/vocational pathway. However, with a high degree of support, other individuals were able to maintain both endeavours for the duration of their sporting career; this is represented by the DC pathway. 


\section{Sporting Pathway}

The first presented vignette illustrates experiences of individuals whose athletic sense of self was particularly salient. This salience was evidenced through their description of how they pursued an increased focus on sport and reduced their commitment to academic or vocational development.

Sporting pathway vignette. I think school was where I got my first thirst for sport. I wouldn't say I was necessarily academic. I gained confidence on the sports field and I was known at school for being sporty. It was an area of school where I developed my character and that's how I then learnt to be confident in myself and my abilities. I made quite a lot of progress early on. I went to my first European championships and raced well against the girls that were regularly on the British team, and that started me thinking, maybe I could start to look at medalling at these championships. After that, I definitely started to commit to becoming the best athlete that I could possibly be. I don't think I knew what that meant but I think deep down, I thought that I could be a part of that Olympic team one day.

I chose a university that was close to my home club so that I could continue to train with my coach, but, logistically, it was an absolute nightmare. The training base and gym was on the east of the city, the university was in the centre and I lived a couple of miles away from the centre. I was always rushing around. It got to a point where I was just missing lectures and missing classes because I was so tired from training. But that shot me in the foot because, then I didn't know what I was doing, and I would be even further behind. That was making the stress even worse. I was running off five hours sleep a night and combining that with tough training. I just kept on getting ill, so my sporting performances were getting worse. I tried to talk to the university and to the sport, but neither were willing to help with any kind of special arrangements. That's when I started to realise I had to make one decision. Either I carry on with university but then I have to quit sport, or I carry on with my sport but 
that means I have to quit university. From my competition results so far, I knew I could make it as an athlete, so I made the decision; I'm going to focus on sport and withdraw from my university course. From that point on I went from student-athlete to a professional athlete, where I began to be far more meticulous about everything: rest, sleep, nutrition, and training as a whole. That was my job. I was an athlete first and foremost rather than anything else. So my social life, career development and all the rest of it; that was very much number two. But, winning medals along the way was showing me that it was all worthwhile. I did have a small income from doing some work as a coach, but it only happened if I could fit it in around training and mainly in the off-season.

Eventually, I got to the stage as an athlete where I was as good as I'd ever get. I felt like, I've ticked all the boxes I wanted to. It was really tough for me and my head was all over the place. I was terrified about retirement because I knew I didn't have a university degree to fall on to. I barely had any education or work experience. My coaching work helped a little, but it wasn't something that I wanted to do full-time. I didn't really know what I wanted to do because I'd never had to think about it.

Sporting pathway analysis. The accounts illustrated in this vignette highlight the importance of athletic identity in athlete's lives and decision-making. The inductive interviews indicated an understanding of identity that resonated with identity theory, where identity is understood as role- and personal- based self-verification which is both influenced by and sustains social structures (Stryker \& Burke, 2000). Athletic identity, in this case, is understood as the cognitive, affective, behavioural, and social aspect of identifying with the athlete role (Brewer et al., 2000; Murphy et al., 1996). The vignette demonstrates the strengthening of athletic identity through events such as, athletic performance (e.g. reaching or exceeding a sporting goal), or athletic recognition (e.g., coach or peer feedback). This narrative also illustrates that the development and maintenance of an athletic identity has 
1 behavioural connotations, where individual's will formulate decisions based upon upholding

2 commitment to their sporting role (e.g., in this vignette, selecting a university based on being able to train at their home club). This association has also been evidenced in runners, where sporting commitment increases with athletic identity (Horton \& Mack, 2000). In contrast to the accelerated athletic identity development, this pathway is characterised by a lack of identity development relating to their career or educational pursuits (as illustrated by the following quote: 'I wouldn’t say I was necessarily academic').

In this pathway, participants described managing a DC as challenging. These individuals didn't have access to the high degree of social support, institutional support or individual competencies which research has identified as necessary for DC management (e.g., Aquilina, 2013; Debois et al., 2015; De Brandt, Wylleman, Torregrossa, Defruyt, \& Van Rossem, 2017; Li \& Sum, 2017). These difficulties were mostly seen at significant points of transition for the individual (see the athletic career transition model, Wylleman et al., 2013). Experiencing poor athletic performance was particularly problematic for individual's in this pathway because it challenged their understanding of themselves. At these points of difficulty, individuals would reassess their abilities and ambitions. The conclusion that sport and education/vocation are uncomplimentary and a coinciding decision to commit more strongly to sport rather than education/vocation characterises the sporting pathway. This is reflected in Figure 1 as the deviation away from the DC pathway.

An increased commitment to the sporting role led to an increase in athletic performance and a realisation of sporting potential in the short-term. Yet, an increased focus on sporting endeavours also has repercussions on educational/vocational development in the long-term. Participants in the sporting pathway (who had reached athletic retirement, $n=5$ ) went on to report difficulties with retiring from sport. This difficultly was to be expected since a high or unidimensional athletic identity has been widely reported as a barrier to 
1 athletic retirement (see Martin, Fogarty, \& Albion, 2014; Torregrosa, Ramis, Pallarés,

2 Azócar, \& Selva, 2015). The challenges in athletic retirement specific to DC athletes are

3

4

categorised and depicted in Figure 1 in two ways: first, an educational gap, where participants described possessing a discrepancy between their vocational career goal and their educational achievements. This could be due to not attaining the appropriate educational level (as illustrated in the vignette) or due to following an educational pathway that was no longer appropriate for the vocation they wished to pursue after sport. Educational status has previously been recognised as a non-athletic factor that has the potential to affect sport career termination (Cecić Erpič, Wylleman, \& Zupanćić, 2004) and educational attainment in athletes has been a focus for DC practice for a number of years (European Union Expert Group: Education and Training in Sport, 2012). Second, a vocational skills gap represents a differential between actual vocational skills and desired vocational goals. To illustrate, in cases where individuals were able to maintain their educational pursuits whilst prioritising sport (e.g., taking an evening class once a week) and were able to achieve the appropriate educational requirements for their desired post-sport career, these individuals often had no vocational experience and therefore, no opportunity to develop the skills required.

\section{Educational/Vocational Pathway}

The second vignette presents a composite account of individuals who perceived a need to prioritise their educational or vocational goals and reduce their commitment to their sporting goals.

Educational/vocational pathway vignette. I went right through the talent pathways at a young age. I think, in the beginning, my efforts towards school and sport were quite evenly split. I think there was quite a lot of influence from my parents on that. They wanted me to do well in school, but also there was a lot of support for the sport-side of things as well. I think being selected at my first international age-group competition; that really spurred me 
on. I loved getting a taste of that and I had a really good squad as well. We had a load of success that previous groups had never had before. Towards the end of school, I wasn't ready to be a professional athlete. My ability wasn't quite there yet to step-up to the senior ranks. I also didn't have the money to travel, to play professionally, and sustain myself. But, mainly, I didn't want to put all my hopes on sport. This became really apparent to me when I saw one of the older guys get injured at a training camp. He was one of the senior, full-time athletes and that was it for him. His sporting career was over with one injury. After seeing that, I knew that I always needed to have something to fall back on.

I found the transition to the senior level hard. I had a few odd positive results, but for every positive result I probably had six negative results. I was on the edge of the squads at the time, so if I missed training or competitions it was affecting my selection later down the line. Every time I didn't do well it was having a really negative impact on my confidence and my belief in myself as an athlete. One week I'd be thinking, "Yes, I'm going to be an athlete" and then the next week I'd be thinking, "I can't do it anymore". So, because of that up-anddown there was always a plan after university that was not dependent on sport.

After university, sport became a bit of a chore. It just felt like, from a lifestyle perspective, it wasn't fitting in at all. I found managing the two really hard. There wasn't the flexibility that there was at university. I had to be at work 9 till 5 with half an hour lunch, so training had to be done in the morning or evening. Then every weekend I'd be traveling to competitions, competing and getting back late Sunday night, to do it all again Monday. It came to selection for the commonwealth and I didn't make the team. I was devastated because it had been a goal of mine, but I knew that I wanted to work my way up a career ladder and I knew that there's no money in sport anyway. So focusing on my career felt like the right option. Yes, I am a bit sad that I never managed to make anything of it and it feels a bit of a waste, all that time in sport, but I love my job now. 

represents a similar initial athletic development to the sporting pathway, i.e., athletic identity is developed through athletic performance and recognition. However, the educational/vocational pathway differs in the area of career development. Career identity, understood in this study as the extent to which an individual identifies with their educational or vocational roles, is much more prominent for individual's in this pathway than the sporting pathway. As alluded to in the vignette and previous research, DC athletes recognise that sporting success was not guaranteed and that they required an alternative focus, a back-up plan, or preparations for post-sport life (e.g., Aquilina, 2013; Li \& Sum, 2017). For participants in the study, this realisation occurred after events, such as underperforming academically, deselection from talent pathways, experiencing injury, financial difficulty in maintaining a sporting career, or becoming frustrated with a lack of mental stimulation. These findings complement previous research that shows athletes re-evaluate the salience of their athletic identities when they recognise that sports careers are potentially unfeasible (Lally \& Kerr, 2005). As the educational/vocational pathway progresses, it is characterised by a more salient identification with and a prioritisation of educational or vocational pursuits. For these individuals, when DC management is challenging or athletic performance is poor, they are more likely to invest time and resources into their alternative career identity. Similarly to the sporting pathway, the critical point where individuals deviate away from the education (see Wylleman et al., 2013).

DC pathway often occurred around the transition out of school or the transition out of higher

An increased commitment to the educational/vocation role is encapsulated in the sporting gap, see Figure 1. The sporting gap represents three barriers to sport that lead to a premature dropout from elite sport or talent pathways and, therefore, a reduction in the pool of talent for performance sport. First, a talent barrier. Participants described reducing their 
1 commitment to elite sport due to experiences such as, deselection from talent pathways. The

2 educational/vocational vignette above presents a narrative where dropout from elite sport was an inactive decision on behalf of the athlete (e.g., the athlete was deselected from the squad and, therefore, did not reach a sporting goal he had set out from himself). Participants in this study who described similar experiences $(n=3)$ tended to not return to sport at all. Whereas, participants who described an active decision (i.e., they felt in control of their choice not pursue elite sport, $\mathrm{n}=2$ ) still participated in sport at a lower level and held roles as sports personnel, e.g. a coaching role. Second, an education barrier. Participants described a promotion of the elite sport narrative (i.e., the only way to athletic success is through a single-minded dedication to sport; Carless \& Douglas, 2013). This narrative discouraged individuals with a more diverse sense of self and a developed career identity to reduce their commitment to elite sport. The third barrier links closely to this but is a financial barrier and is illustrated in the vignette. Participants in this study, particularly in non-funded or nonprofessional sports, were deterred from pursuing elite sport due to the financial challenge it would pose to compete in sport without an income.

\section{Dual Career Pathway}

The third vignette illustrates the simultaneous development of athletic and career identity from initial stages of a DC to athletic retirement. Through this pathway individuals have the potential to achieve both their educational and their sporting goal.

Dual career vignette. I always used to play a lot of sport. In the beginning I was just like any normal student, just doing sport on the side. Then, as I got better in sport and I began to focus more on competing, I had some special arrangements put in place at school. I had some lessons which I didn't have to take part in. But, I still had to do the work in my own time because I had to do the same exams as everyone else. I just kept trying to do my training on the side, which worked fine since I was only training once a day. My first coach was really 
1 influential in my career because she implemented all the values that you need, like working

2 hard, planning ahead, staying organised. She was a teacher and she always put a lot of emphasis on the education side. So from pretty much the start of my competitive sporting career I always wanted to do both. I always wanted to achieve a high level in sport, but I also always wanted to be top in academics as well.

When I went to university it was different. I had a completely different training regime. I started training a lot more and then I improved quite a lot. In some ways, university was easier to manage than school, because the academic side was less fixed, you could work a lot more in your own time, and you didn't have lessons all day/every day. And the sport side of things was set up for us to do an education. If we couldn't make a session due to a lecture, then the coach would give you the session to do in your own time. On the other hand, you have to do a lot more work than you did at school and you start to train more. Sometimes it was quite draining, I felt empty and tired. But, again, the university and sport were really great and I just made sure I was always organised in advance. If I knew I had a big competition coming up, and I foresaw that I would be really pushed for time, then I would make sure I did the work early or I spoke to the relevant people who could move my deadlines for me. If I had exams, I had to miss a session or two, here or there, but I'd catch up the training later in the day. In my second year at university I managed to get a medal at the European Championships. That performance triggered that I wanted to put even more into sport. I decided to split my final year to give me more time to train, but I still wanted to carry on with the academic work. I thought about just focusing on sport a lot and it could have been really beneficially for my performance, but I didn't want to put all my eggs in one basket. I knew that you could try train as hard as you want, you could do everything you can, but, sometimes, it's just not meant to be. You could get an injury tomorrow and it would all be 
1 over. That stopped me from dropping out of university. I was always aware that there would

2 be a moment when I had to stop sport and do something else.

After university I had to take the decision if I would go full-time sport and train for the Olympics. I didn't really want to do it because, you train in the morning and the evening, but you have so much free time in between and I think I'd just get bored. I also knew what job I wanted to do and that didn't change just because I had the chance to win an Olympic medal. So, I tried to find a job which would give me a lot of flexibility. I worked part-time and I think that worked well. Just to, you know, get your mind off sport a bit, in between sessions. It was a little bit more difficult with having time off than university was. My boss is really into his sport, so he was very understanding of the requirements. He gave me a few extra days off and I was able to be really flexible with my job. I could take my laptop to training and be working pretty much from anywhere. When it came to retiring from sport, I found it a lot easier than some of my peers. Sure, it was a big adjustment but I knew the job, I knew what I needed to do, so it was just doing what I'd already been doing for years.

Dual career pathway analysis. The DC pathway represents the simultaneous development of sporting and educational/vocational identities. Participants in this pathway experienced both events that strengthened their athletic identity (e.g., positive athletic performance) and events that encouraged them to develop to their career identity (e.g., the risk injury presents to the sole pursuit of sport). As a result, they would describe both roles as important to their sense of self. These findings support earlier research, for example: Ryba et al., (2017) described the styles that junior athletes use to construct their future careers and observed a similar interdependent relationships of sport and education. In addition, Chamorro, Torregrosa, Sánchez Oliva, García Calvo, \& León, (2016) categorised youth athletes based on their future ambitions, the largest of these groups (288 out of 478) held balanced perceptions of the importance of achievements in sport, educational, and private 
1 life. DC benefits, including a need to focus on more than sport, a sense of security, and

2 consideration for life after sport, which have been identified in previous literature (see

3 Aquilina, 2013) were used as justifications by participants for continuing on a DC pathway. Less than half $(n=6)$ of the participants in this study maintained their sporting and educational pursuits throughout their development. In order to manage both endeavours, participants in the DC pathway engaged in a number of management strategies to ease this challenge, such as selecting educational, vocational, and sporting settings that are flexible to the demands of the alternative pursuit (Gledhill \& Harwood, 2015; Pink et al., 2015, 2018; Tekavc et al., 2015), the development of communication and social skills (Ryan, 2015), seeking advice and assistance from an understanding support network (Aquilina, 2013), and developing effective DC skills (Brown et al., 2015; De Brandt et al., 2017). Interestingly, participants in the DC pathway often described brief periods of time where one career path was prioritised before athletes would return to a more balanced focus on both careers. This fluctuation in focus and prioritisation was utilised as a temporary coping mechanism for periods of particularly high demand on time or energy such as spells of exams or competitions and is represented in Figure 1. Furthermore, participants in this pathway reported a smooth transition out of sport as they had invested in an alternative identity (Knights, Sherry, \& Ruddock-Hudson, 2016).

\section{Discussion}

In this study, the researchers used a constructivist grounded theory method to identify and examine individuals' experiences and outcomes of sport and education or vocational development, with the intention to establish an overarching theory of DC pathways. The findings from qualitative interviews and analysis of the extant literature clearly present three pathways: a DC pathway which represents a balance between sport and education/vocation, a sporting pathway which represents a sport-dominant approach to DC, and an 
1 educational/vocational pathway which represents a education/vocation dominant approach.

2 The finding intricately link each pathway to differences in identity development. The DC

3 pathway involves individuals simultaneously developing their sporting and educational or

4 vocational abilities and identities, resulting in reaching one's potential in both domains.

5 Theoretically, this development could represent an equal progression in both domains; in

6 reality, participants indicated that, on occasion, this progression fluctuated at different stages

7 of development. The sporting and educational/vocational pathways both involve an

8 acceleration in development in one domain (and a corresponding sacrifice in the other

9 domain), which potentially results in realising potential in one domain sooner while risking

10 failure to realise potential in the other domain.

The findings of this study support research that suggests effectively managing sporting and educational/vocational endeavours can develop a variety of well-being benefits and enable a smooth transition in to life after sport (Miller \& Kerr, 2002; Taylor et al., 2005). However, in practice, a parallel balance of DC requires a high degree of social support to carefully manage numerous institutional and individual factors (e.g., Aquilina, 2013; Debois et al., 2015; De Brandt et al., 2017; Knight et al., 2018; Li \& Sum, 2017; Pink et al., 2018). The DC pathway, therefore, is not always plausible and barriers to DC management must be considered by practitioners to ensure individuals who want to pursue a DC pathway are able to achieve their potential in both of their pursuits. As an alternative to parallel DCs, participants reduced their focus towards one of their endeavours, presented by this study as either the sporting pathway or the educational/vocational pathway. The deviations away from the DC pathway, were commonly perceived in conjunction with athletic and academic transitions (e.g., the transition from school to further education, the transition from junior to senior athletic level, and the transition from further education to vocation). Since these developmental transitions are considered to be normative and predictable (Wylleman et al., 
1 2013), practitioners are able to anticipate periods of difficulty and provide opportunities for

2 athletes to develop the skills to overcome these in advance (MacNamara \& Collins, 2010).

3 Advanced preparation for transitions, implement of management strategies including

4 adjusting balance for a temporary period of time, and increased support from practitioners

5 could reduce barriers to DC management and better enable the DC pathway for individuals

6 who wish to pursue it.

This study adds to the emerging body of research, which understands DC athletes as a heterogeneous group with individual pathways, by exploring this conceptualisation across the DC lifespan. Through drawing the previous literature (e.g., Aunola et al., 2018; Chamarro et al., 2016; Ryba et al., 2017; Stambuolva et al., 2015) and inductive interview data together via the grounded theory method (Charmaz, 2006), this study presents an overarching, lifespan perspective of the DC experience and establishes three distinct DC pathways. In doing this, this study presents further understanding of the specific experiences and the link between these experiences and DC outcomes (i.e., the sporting, educational, and vocational gap). Interesting similarities between young athletes' perceived future selves (Ryba et al., 2017), their perceived importance of different life domains (Chamorro et al., 2016), their motivational profiles (Aunola et al., 2018), and the retrospective narratives of DC athletes' experiences (the current study). All three studies identified a group that reflects a balance between sport and education (the DC pathway). In addition, all three studies identified groups which illustrate one pursuit holding a dominant position. The current study and previous literature (Chamorro et al., 2016; Aunola et al., 2018) separated the groups into a sporting dominant category and an educational/vocational dominant category. These studies suggest athletes construct their career styles from a young age and these constructions impact the actions they take. 
The study contributes further to the literature by demonstrating the outcomes of each

2 pathway as 'gaps'. These are described in the vignettes, represented in Figure 1, and

3 discussed in the analysis. It is argued that these gaps have implications for research and

4 practice; hence, the term 'mind the gap'. If we first consider the educational gap, which

5 represents the discrepancy between athletes' attained education and the education they

6 require for the post-sport career they desire. Education status as a non-athletic factor that

7 impacts athletic retirement has been shown in the transition literature (Cecić Erpič et al.,

8 2004). In addition, many athlete support programs focus on developing athletes' skills to

9 cope with sport and education (Aquilina \& Henry, 2010; De Brandt et al., 2017) in order to

10 avoid individual's experiencing this gap. However, the support for athletes in a vocation and the evidence-base for supporting vocational skill development for DC athletes is still lacking. The study suggests that DC support services should consider a focus beyond the educational goals of the individual and consider supporting vocational skills development in preparation for athletic career termination. An awareness of and preparation for this potential gap could ease the transition out of sport for retiring athletes in the sporting pathway.

The sporting gap represents talent, education, and financial barriers to DC athlete's commitment to sport, which have implications for performance sport, sports management, and sport participation. First, it is recognised that talent selection is a necessary element of elite sport, however the point at which selection occurs and the approach towards talent selection versus talent development is a decision of sport management. A focus on early talent selection means that resources can be focused towards fewer numbers of athletes, however it assumes future sporting potential is predicted by current sporting success and does not recognise the impact late developing athletes can have at the elite level (Bailey \& Collins, 2013; Green, 2005). For example, many UK elite performers are selected via talent transfer programs between the age of 18-25 (Rees, et al., 2016; Vaeyens, Güllich, Warr, \& 
1 Philippaerts, 2009; Baker, Schorer, \& Wattie, 2018). Second, an early and negative

2 termination of elite sporting pursuits was associated in this study with a tendency to terminate engagement in sport all together. At this stage, this association is tentative, however research suggests time spent competing in sport as an athlete is considered an important factor in effective coach development (Gilbert, Côté \& Mallet, 2006; Lemyre, Trudel, \& DurandBush, 2007). Thirdly, sporting organisation need to consider their promotion of the elite sport narrative as the only path to succeed in sport and instead their openness to the promotion of elite success alongside an education. Sport organisations should consider their approach to talent selection and the consequences of early selection and a narrow talent pathway model for sport participation, inclusion and encouraging future sport coaches and sport management.

While the 'mind the gap' theory supports existing research (e.g., Stambulova et al., 2015; Ryba et al., 2017; Aunola et al., 2018), the use of a grounded theory approach has enabled researchers to add further value to current understandings in three important ways: first, the findings provide comprehensive accounts of different experiences of combining sport with an education or vocation over the DC lifespan. The composite vignettes provide researchers and practitioners with dense descriptions of the experiences which are associated with each pathway. Through gaining a deeper understanding of this, practitioners (e.g., lifestyle advisors and DC providers) can relate the framework to the DC individual they are working with and the DC pathway they are most closely following. Second, in this study, these experiences are persuasively linked to potential outcomes of each pathway (i.e., the sporting, educational, and vocational gaps) and the implications these outcomes may have on practice and research, enabling practitioners to better inform the DC athletes they support of the options available to them (i.e., the different pathways) and the consequences of these choices (i.e., the outcomes) to enable them to make informed career decisions. Further, by 
1 outlining these practical implications these gaps can have the current study illustrates the

2 consideration for sport and sport management that DC pathways present. Sport organisations

3

4 could benefit from developing similar typologies of DC pathways that exist within their organisation and ensure the appropriate support is available for supporting and addressing the potential outcomes of pathways.

Finally, the developed framework offers theoretical promise for future empirical analysis. The integration and comparison of the findings with previous research, which has largely focused on school-aged or university-aged DC athletes, via the grounded theory has facilitated the conclusions presented in this study. While the introduction of inductive data enabled the development of a theory that encapsulates the DC lifespan and, therefore, extends current understanding. The study has highlighted the importance of future research in maintaining sensitivity to different pathways in the development of sport and educational/vocational careers. Despite these advances, the grounded theory currently is unable to explain the mechanisms that form different pathways, this is an area for future study. Further research to understand the specific characteristics (in particular, identity) of individuals in different pathways would also be beneficial. Furthermore, understanding the distribution of individuals in each pathway could provide valuable information regarding the most effective division of support services for sport organisations.

In line with a constructivist epistemology, the proposed theory remains open to modification and to changing understandings of the phenomena. The grounded theory is, at this stage, a substantive theory, which is intended to reveal structures of knowledge (Glaser \& Strauss, 1967). It builds generalizations on observations of one particular area, in this case DC athletes educated in the British context. The theory is only generalizable to other contexts and other participants experiencing similar phenomena. The theory can be adapted to include participants outside of this context with further study of diverse, substantive cases and a 
1 comparative analysis. This kind of further research would enable the development of the

2 substantive theory into a formal theory. 


\section{References}

Aquilina, D. (2013). A study of the relationship between elite athletes' educational development and sporting performance. International Journal of the History of Sport, 30(4), 374-392. doi:10.1080/09523367.2013.765723

Aquilina, D., \& Henry, I. (2010). Elite athletes and university education in Europe: a review of policy and practice in higher education in the European Union Member States. International Journal of Sport Policy, 2(1), 25-47.

Atkinson, R. (1998). The life story interview. Thousand Oaks, CA: Sage. doi:10.4135/9781412986205

Aunola, K., Selänne, A., Selänne, H., \& Ryba, T. V. (2018). The role of adolescent athletes' task value patterns in their educational and athletic career aspirations. Learning and Individual Differences, 63, 34-43. doi:10.1016/j.lindif.2018.03.004

Bailey, R., \& Collins, D. (2013). The standard model of talent development and its discontents. Kinesiology Review, 2, 248-259. doi:10.1123/krj.2.4.248

Baker, J., Schorer, J., \& Wattie, N. (2018). Compromising talent: Issues in identifying and selecting talent in sport. Quest, 70(1), 48-63. doi:10.1080/00336297.2017.1333438

Bimper, A. Y. (2014). Game changers: The role athletic identity and racial identity play on academic performance. Journal of College Student Development, 55(8), 795-807. doi:10.1353/csd.2014.0078

Blodgett, A. T., Schinke, R. J., Smith, B., Peltier, D., \& Pheasant, C. (2011). In indigenous words: Exploring vignettes as a narrative strategy for presenting the research voices of Aboriginal community members. Qualitative Inquiry, 17(6), 522-533. https://doi.org/10.1177/1077800411409885

Brewer, B. W., Van Raalte, J. L., \& Petitpas, A. J. (2000). Self-identity issues in sport career transitions. In D. Lavallee \& P. Wylleman (Eds.), Career transitions in sport: 
International perspectives (pp. 29-43). Morgantown, WV: Fitness Information Technology. doi:10.1037/0090-5550.45.1.20

Brown, C., Glastetter-Fender, C., \& Shelton, M. (2000). Psychosocial identity and career control in college student-athletes. Journal of Vocational Behavior, 56(1), 53-62. doi:10.1006/jvbe.1999.1691

Brown, D. J., Fletcher, D., Henry, I., Borrie, A., Emmett, J., Buzza, A., \& Wombwell, S. (2015). A British university case study of the transitional experiences of studentathletes. Psychology of Sport and Exercise, 21, 78-90. doi:10.1016/j.psychsport.2015.04.002

Burke, P. J. (2016). Elements of inquiry: A guide for consumers and producers of research. New York, NY: Routledge.

Carless, D., \& Douglas, K. (2013). Living, resisting, and playing the part of athlete: Narrative tensions in elite sport. Psychology of sport and exercise, 14(5), 701-708. doi:10.1016/j.psychsport.2013.05.003

Cecić Erpič, S., Wylleman, P., \& Zupančič, M. (2004). The effect of athletic and non-athletic factors on the sports career termination process. Psychology of Sport and Exercise, 5(1), 45-59. doi: 10.1016/s1469-0292(02)00046-8

Chamorro, J., Torregrosa, M., Sánchez Oliva, D., García Calvo, T., \& León, B. (2016). Future achievements, passion and motivation in the transition from junior-to-senior sport in Spanish young elite soccer players. The Spanish Journal of Psychology, 19, E69. doi:10.1017/sjp.2016.71

Champ, F. M., Nesti, M. S., Ronkainen, N. J., Tod, D. A., \& Littlewood, M. A. (2018) An exploration of the experiences of elite youth footballers: The impact of organizational culture. Journal of Applied Sport Psychology, 0, 1-22. doi:10.1080/10413200.2018.1514429 
1 Charmaz, K. (2006). Constructing grounded theory: A practical guide through qualitative analysis. London: Sage.

Cosh, S., \& Tully, P. J. (2014). “All I have to do is pass”: A discursive analysis of student athletes' talk about prioritising sport to the detriment of education to overcome stressors encountered in combining elite sport and tertiary education. Psychology of Sport and Exercise, 15(2), 180-189. doi:10.1016/j.psychsport.2013.10.015

Creswell, J. W. (2007). Qualitative inquiry and research design: Choosing among five traditions ( $2^{\text {nd }}$ ed.). Thousand Oaks, CA: Sage.

Debois, N., Ledon, A., \& Wylleman, P. (2015). A lifespan perspective on the dual career of elite male athletes. Psychology of Sport and Exercise, 21, 15-26. doi:10.1016/j.psychsport.2014.07.011

De Brandt, K., Wylleman, P., Torregrossa, M., Defruyt, S., \& Van Rossem, N. (2017). Student-athletes' perceptions of four dual career competencies. Revista de psicología del deporte, 26(4), 28-33.

Ely, M., Vinz, R., Downing, M., \& Anzul, M. (2003). On writing qualitative research: Living by words. London: Routledge.

European Union Expert Group: Education and Training in Sport. (2012). EU guidelines on dual careers of athletes: Recommended policy actions in support of dual careers in high-performance sport. Sport Unit of the Directorate-General for Education and Culture of the European Commission, Brussels (2012). Retrieved from http://ec.europa.eu/sport/news/20130123-eu-guidelines-dualcareers en.htm

Gilbert, W., Côté, J. \& Mallett, C. (2006). Developmental paths and activities of successful sport coaches. International Journal of Sports Science \& Coaching, 1(1), 69-76. doi:10.1260/174795406776338526 
1 Glaser, B. G. (1992). Emergence vs forcing: Basics of grounded theory analysis. Mill Valley, CA: Sociology Press.

Glaser, B. G., \& Strauss, A. (1967). The discovery of grounded theory. London: Weidenfield \& Nicolson.

Gledhill, A., \& Harwood, C. (2015). A holistic perspective on career development in UK female soccer players: A negative case analysis. Psychology of Sport and Exercise, 21(1), 65-77. doi:10.1016/j.psychsport.2015.04.003

Green, B. C. (2005). Building sport programs to optimize athlete recruitment, retention, and transition: Toward a normative theory of sport development. Journal of Sport Management, 19(3), 233-253. doi:10.1123/jsm.19.3.233

Hallberg, L. R. (2006). The "core category" of grounded theory: Making constant comparisons. International Journal of Qualitative Studies on Health and Well-being, 1(3), 141-148. doi:10.3402/qhw.v1i3.4927

Hings, R. F., Wagstaff, C. R. D., Anderson, V., Gilmore, S., Thelwell, R. C. (2018) Professional challenges in elite sports medicine and science: Composite vignettes of practitioner emotional labor. Psychology of Sport and Exercise, 35, 66-73. https://doi.org/10.1016/j.psychsport.2017.11.007.

Holt, N., \& Dunn, J. (2004). Toward a Grounded Theory of the Psychosocial Competencies and Environmental Conditions Associated with Soccer Success. Journal of Applied Sport Psychology, 16(3), 199-219. doi:10.1080/10413200490437949

Holt, N. L., \& Tamminen, K. A. (2010). Improving grounded theory research in sport and exercise psychology: Further reflections as a response to Mike Weed. Psychology of Sport and Exercise, 11(6), 405-413. doi:10.1016/j.psychsport.2009.12.002

Horton, R. S., \& Mack, D. E. (2000). Athletic identity in marathon runners: Functional focus or dysfunctional commitment? Journal of Sport Behavior, 23(2), 101-119. 
1 Hutchinson, A. J., Johnston, L. H., \& Breckon, J. D. (2013). A grounded theory of successful long-term physical activity behavior change. Qualitative Research in Sport, Exercise, and Health, 5, 109-129.

Isoard-Gautheur, S., Guillet-Descas, E., Gaudreau, P., \& Chanal, J. (2015). Development of burnout perceptions during adolescence among high-level athletes: A developmental and gendered perspective. Journal of Sport \& Exercise Psychology, 37(4), 436-48. doi:10.1123/jsep.2014-0251

Knight, C., Harwood, C., \& Sellars, P. (2018). Supporting adolescent athletes' dual careers: The role of an athlete's social support network. Psychology of Sport and Exercise, 38, 137-147. doi: 10.1016/J.psychsport.2018.06.007

Knights, S., Sherry, E., \& Ruddock-Hudson, M. (2016). Investigating elite end-of-athleticcareer transition: A systematic review. Journal of Applied Sport Psychology, 28(3), 291-308. doi:10.1080/10413200.2015.1128992

Lally, P. S., \& Kerr, G. A. (2005). The career planning, athletic identity, and student role identity of intercollegiate student athletes. Research Quarterly for Exercise and Sport, 76(3), 275-285. doi:10.1080/02701367.2005.10599299

Lavallee, D., \& Robinson, H. K. (2007). In pursuit of an identity: A qualitative exploration of retirement from women's artistic gymnastics. Psychology of Sport and Exercise, 8(1), 119-141. doi:10.1016/j.psychsport.2006.05.003

Lemyre, F., Trudel, P., \& Durand-Bush, N. (2007). How youth-sport coaches learn to coach. The Sport Psychologist, 21(2), 191-209. doi:10.1112/tsp.21.2.191

Levitt, H. M., Motulsky, S. L., Wertz, F. J., Morrow, S. L., \& Ponterotto, J. G. (2017). Recommendations for designing and reviewing qualitative research in psychology: Promoting methodological integrity. Qualitative Psychology, 4(1), 2-22. doi:10.1037/qup0000082 
1 Li, M., \& Sum, R. K. W. (2017). A meta-synthesis of elite athletes' experiences in dual career development. Asia Pacific Journal of Sport and Social Science, 6(2), 1-19. doi: $10.1080 / 21640599.2017 .1317481$

Martin, L. A., Fogarty, G. J., \& Albion, M. J. (2014). Changes in athletic identity and life satisfaction of elite athletes as a function of retirement status. Journal of Applied Sport Psychology, 26(1), 96-110. doi:10.1080/10413200.2013.798371

MacNamara, Á., \& Collins, D. (2010). The role of psychological characteristics in managing the transition to university. Psychology of Sport and Exercise, 11(5), 353-362. doi:10.1016/j.psychsport.2010.04.003

Melendez, M. C. (2009). Psychosocial influences on college adjustment in division I studentathletes: The role of athletic identity. Journal of College Student Retention: Research, Theory \& Practice, 11(3), 345-361. doi:10.2190/cs.11.3.c

Miller, P. S., \& Kerr, G. (2002). The athletic, academic and social experiences of intercollegiate student-athletes. Journal of Sport Behavior, 25(4), 346-367.

Mills, J., Bonner, A., \& Francis, K. (2006). Adopting a constructivist approach to grounded theory: Implications for research design. International Journal of Nursing Practice, 12(1), 8-13. doi:10.1111/j.1440-172X.2006.00543

Murphy, G. M., Petitpas, A. J., \& Brewer, B. W. (1996). Identity foreclosure, athletic identity, and career maturity in intercollegiate athletes. The Sport Psychologist, 10(3), 239-246. doi:10.1123/tsp.10.3.239

O’Malley, L., Winter, S., \& Holder, T. (2018). ‘Always picking country over club’: A creative non-fiction story of an international coach-athlete-coach triad. Qualitative Research in Sport, Exercise and Health, 10(2), 223-237. doi:10.1080/2159676x.2017.1367716 
1 Patton, M. Q. (2002). Qualitative research and evaluation methods (3 ${ }^{\text {rd }}$ ed.). Newbury Park,

2 CA: Sage.

Petitpas, A. J., Brewer, B. W., \& Van Raalte, J. L. (1996). Transitions of the student athlete: Theoretical, empirical, and practical perspectives. In E. F., Etzel, A. P., Ferrante, \& J. W. Pinkney (Eds.), Counselling college student athletes: Issues and interventions, 2nd edition (pp. 137-156). Morgantown, WV: Fitness Information Technology.

Pink, M. A., Lonie, B. E., \& Saunders, J. E. (2018). The challenges of the semi-professional footballer: A case study of the management of dual career development at a Victorian Football League (VFL) club. Psychology of Sport and Exercise, 35, 160-170. doi:10.1016/j.psychsport.2017.12.005

Pink, M., Saunders, J., \& Stynes, J. (2015). Reconciling the maintenance of on-field success with off-field player development: A case study of a club culture within the Australian Football League. Psychology of Sport and Exercise, 21, 98-108. doi:10.1016/j.psychsport.2014.11.009

Rees, T., Hardy, L., Güllich, A., Abernethy, B., Côté, J., Woodman, T., ... \& Warr, C. (2016). The great British medalists project: a review of current knowledge on the development of the world's best sporting talent. Sports Medicine, 46(8), 1041-1058.

Robinson, O. C. (2014). Sampling in interview-based qualitative research: A theoretical and practical guide. Qualitative Research in Psychology, 11(1), 25-41. doi:10.1080/14780887.2013.801543

Ryan, C. (2015). Factors impacting carded athletes' readiness for dual careers. Psychology of Sport and Exercise, 21, 91-97. doi:10.1016/j.psychsport.2015.04.008

Ryba, T. V., Stambulova, N. B., Ronkainen, N. J., Bundgaard, J., \& Selänne, H. (2015). Dual career pathways of transnational athletes. Psychology of Sport and Exercise, 21, $125-$ 134. doi:10.1016/j.psychsport.2014.06.002 
1 Ryba, T. V., Stambulova, N. B., Selänne, H., Aunola, K., \& Nurmi, J. (2017). "Sport has always been first for me" but "all my free time is spent doing homework": Dual career styles in late adolescence. Psychology of Sport and Exercise, 33, 131-140. doi:10.1016/j.psychsport.2017.08.011

Schinke, R. J., Blodgett, A. T., McGannon, K. R., Ge, Y., Oghene O., \& Seanor, M. (2017) Adjusting to the receiving country outside the sport environment: A composite vignette of Canadian immigrant amateur elite athlete acculturation. Journal of Applied Sport Psychology, 29(3), 270-284. doi:10.1080/10413200.2016.1243593

Singer, J. N. (2008). Benefits and detriments of African American male athletes' participation in a big-time college football program. International Review for the Sociology of Sport, 43(4), 399-408. doi:10.1177/1012690208099874

Smith, B. (2016). Narrative analysis: How can it be done? In B. Smith, A. Sparkes (Eds.), Routledge handbook of qualitative research in sport and exercise (pp. 260-273). UK: Routledge.

Spalding, N. J., \& Phillips, T. (2007). Exploring the use of vignettes: From validity to trustworthiness. Qualitative Health Research, 17(7), 954-962. doi:10.1177/1049732307306187

Sparkes, A. C. (2002). Fictional representations: On difference, choice, and risk. Sociology of Sport Journal, 19, 1-24. doi:10.1123/ssj.19.1.1

Stambulova, N. (2003). Symptoms of a crisis-transition: A grounded theory study. In N. Hassmén (Ed.), Svensk idrottspsykologisk förening (pp. 97-109). Örebro: Örebro University Press.

Stambulova, N., Alfermann, D., Statler, T., \& Côté, J. (2009). ISSP position stand: Career development and transitions of athletes. International Journal of Sport and Exercise Psychology, 7(4), 395-412. doi:10.1080/1612197x.2009.9671916 
1 Stambulova, N. B., Engström, C., Franck, A., Linnér, L., \& Lindahl, K. (2015). Searching for an optimal balance: Dual career experiences of Swedish adolescent athletes. Psychology of Sport and Exercise, 21, 4-14. doi:10.1016/j.psychsport.2014.08.009

Stambulova, N. B., \& Wylleman, P. (2015). Special issue: Dual career development and transitions. Psychology of Sport and Exercise, 21, 1-134. doi:10.1016/j.psychsport.2015.05.003

Strauss, A., \& Corbin, J. (1990). Basics of qualitative research (Vol. 15). Newbury Park, CA:Sage.

Stryker, S., \& Burke, P. J. (2000). The past, present, and future of an identity theory. Social psychology quarterly, 284-297.

Taylor, J., Ogilvie, B., \& Lavallee, D. (2005). Career transition among elite athletes: Is there life after sports? In J. M. Williams (Ed.), Applied sport psychology: Personal growth to peak performance (pp. 595-615). Columbus, OH:McGraw-Hill.

Tekavc, J., Wylleman, P., \& Cecić Erpič, S. (2015). Perceptions of dual career development among elite level swimmers and basketball players. Psychology of Sport and Exercise, 21, 27-41. doi:10.1016/j.psychsport.2015.03.002

Torregrosa, M., Ramis, Y., Pallarés, S., Azócar, F., \& Selva, C. (2015). Olympic athletes back to retirement: A qualitative longitudinal study. Psychology of Sport and Exercise, 21, 50-56. doi: 10.1016/j.psychsport.2015.03.003

Vaeyens, R., Güllich, A., Warr, C. R., \& Philippaerts, R. (2009). Talent identification and promotion programmes of Olympic athletes. Journal of Sports Sciences, 27(13), 1367-1380. doi:10.1080/02640410903110974

Weed, M. (2009). Research quality considerations for grounded theory research in sport and exercise psychology. Psychology of Sport and Exercise, 10(5), 502-510. doi:10.1016/j.psychsport.2009.02.007 
1 Weed, M. (2010). A quality debate on grounded theory in sport and exercise psychology? A

2 commentary on potential areas for future debate. Psychology of Sport and Exercise, 11(6), 414-418. doi:10.1016/j.psychsport.2010.07.001

Weed, M. (2017). Capturing the essence of grounded theory: The importance of understanding commonalities and variants. Qualitative Research in Sport, Exercise and Health, 9(1), 149-156. doi:10.1080/2159676x.2016.1251701

Wylleman, P., Alfermann, D., \& Lavallee, D. (2004). Career transitions in sport: European perspectives. Psychology of Sport and Exercise, 5, 7-20. doi:10.1016/S1469210292(02)00049-3

Wylleman, P., \& Lavallee, D. (2004). A developmental perspective on transitions faced by athletes. In M. Weiss (Ed.), Developmental Sport and Exercise Psychology: A Lifespan Perspective (pp. 503-523). Morgantown, WV: Fitness Information Technology.

Wylleman, P., Reints, A., \& De Knop, P. (2013). A developmental and holistic perspective on athletic career development. In P. Sotiaradou, \& V. De Bosscher (Eds.), Managing high performance sport (pp. 159 - 182). New York, NY: Routledge. 
Table 1

Summary of participant characteristics, including sporting, educational, and/or vocational experiences.

Pseudonym Gender

Sporting and educational / vocational journey

Attended university while competing at the international university

Jake

Male

level. Currently studying a part-time postgraduate degree and attending national squad selection events.

Sara

Female

Selected a university based on high-level of sport and the degree subject. Currently a full-time undergraduate student and competing at a senior international level.

Focused on sport for a year after compulsory education to focus on

Joel Male training and transition to senior level but maintained work experience. Currently a full-time undergraduate student and attending Olympic selection events.

After compulsory education played sport professionally and

internationally. During this time completed an undergraduate online

Leonard Male degree part-time. Retired from sport and completed a post-graduate

degree. Currently pursuing his post-sport career as a life-style coach and mentor.

Selected a university based on high-level of sport and the degree subject, competed at an international age-group level during this time.

Adam Male Suffered an injury that encouraged the maintenance of a focus on education and a vocational career outside of sport. Currently a fulltime undergraduate student and competing at a national level.

Terminated university early to focus sport become world champion

Ronald Male and Olympic medallist. Worked part-time around sport. Recently retired from sport but does not have the education or vocational skills required for his vocational career aspirations.
Pathway (according to the proposed model) and explanation

DC pathway - equal focus towards both vocational career and sporting ambitions. Using management strategy of part-time study.

DC pathway - always maintained an equal focus towards education, vocational career goals and sporting goals

DC pathway -short-term prioritisations of sport, particularly over a transition, but there was always a focus/progression of both careers.

Sporting pathway - prioritisation of sport, maintain vocational career development around sport. After retirement, needed further education to go onto a post-sport career.

DC pathway - maintains a focus on both education and vocational career and on sport through his journey.

Sporting pathway - sacrificed education and vocational career goals to pursue sport. Did maintain a vocation but was not relevant to post-athletic career aspirations. 
Combined full-time undergraduate and part-time postgraduate

Liam Male

Female

Female

Abigail

Female

Dominic

Male

Rachel

Female

Alice

Female

Jamal

Male degrees with competing at an international level and at an Olympic games. Currently working part time as a teacher, whilst competing internationally.

After university increased focus towards sport, competed

international, at the Olympics and becoming world champion. During this sport prioritisation vocational career aspirations changed, and undergraduate degree was no longer relevant. Currently a full-time athlete exploring career options and work experience around sport. Full-time job role in defence career before becoming a professional athlete. Shifted focus towards sport to become multiple Olympic medallist. Returned to work during off-season to maintain vocational career. Recently retired and described a lack of workplace experience.

After university, selected a job that would work around a focus on sport, competed internationally and at an Olympic games. Retired and retrained to a career as a journalist. Currently working as a journalist. Maintained competing at an international level throughout university. Prioritised career after university and was deselected from the national squad.

During compulsory education, selected into a national senior training program, was shortly deselected from the program and attended university. No longer competes in this sport, currently a full-time undergraduate student.

Maintained competing at an international level during compulsory education, higher education and now currently combining international competition with a vocation.

After compulsory education, competed at as a professional senior athlete, whilst coaching part-time around sport. Recently retired but does not want to pursue coaching.
DC pathway - equal focus on sporting and education/vocational goals were maintained throughout the athletic lifespan.

Sporting pathway - prioritise sport and sacrificed of vocational career aspirations. Currently exploring vocational aspirations and work experience when it works with sport.

Sporting pathway - prioritised sporting ambitions over vocational career and lacked workplace experience.

Sporting pathway - prioritised sport over vocational career, needed further education and work experience upon athletic retirement. Educational/ Vocational pathway - focus on vocational career to the detriment of sporting career

Educational/ Vocational pathway deselection encouraged a focus on education and a dropout from that sport.

DC pathway - equal focus towards sport and vocational career throughout the lifespan.

Sporting pathway - prioritisation of sport and sacrifice of education and vocational experience. 
Competing at an international under $23 \mathrm{~s}$ level during university but

Gabrielle Female suffered a career-ending injury. Now no longer competes in sport, is a full-time undergraduate student.

Competing at a national age-group level during compulsory

Harry Male education and university. Was not able to compete in the senior international competitions due to financial restraints, now retired from sport and pursuing a full-time postgraduate degree.

Competed at an international age-group level during compulsory

Ellen

Female education and university, was unable to transition to the senior level and suffered injuries. Retired from sport and is currently a full-time post-graduate student

Educational/ Vocational pathway prioritisation of education due to a career ending injury.

Educational/ Vocational pathway prioritisation of education and vocational career due to financial barriers.

Educational/ Vocational pathway prioritisation of education and vocational career due to deselection and injury. 


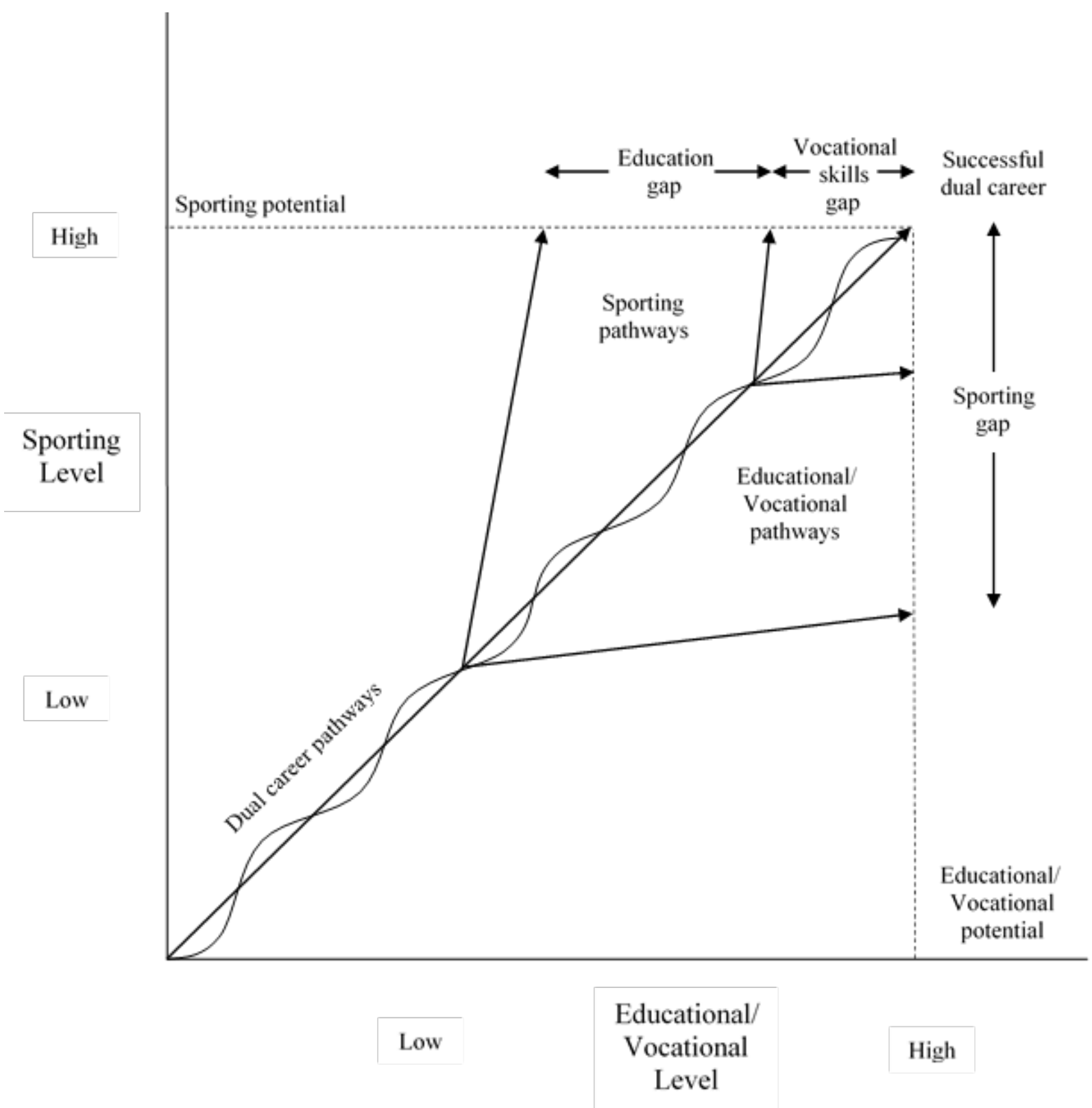

Figure 1. A grounded theory of dual career pathways in sport. 